American J. of Engineering and Applied Sciences 2 (4): 699-702, 2009

ISSN 1941-7020

(C) 2009 Science Publications

\title{
A Novel High Stop Band All Complementary MOSFET Switched-Capacitor Filter
}

\author{
Moussa Abdallah and Ismail Nabhan \\ Department of Electronics Engineering, Princess Sumaya University for Technology, \\ P.O. Box 1438, Amman, 11941 Jordan
}

\begin{abstract}
Problem statement: Filters are widely used in various applications including communications, electronics and biomedical engineering. The performance and size of the filter is of interest especially in chip implementation. A switched-capacitor low-pass filter was designed and simulated using a $0.18 \mu \mathrm{m}$ 1P6M CMOS technology. Approach: This circuit design offered obvious advantages in increasing the stopband attenuation, reducing passband ripple and achieving accurate frequency response. Results: This circuit achieved $53 \mathrm{~dB}$ stop band attenuation, less than $0.1 \mathrm{~dB}$ passband ripple, a $5 \mathrm{KHz}$ cut-off frequency, a $100 \mathrm{KHz}$ stopband frequency and consumes $6 \mathrm{~mW}$ from a $2 \mathrm{~V}$ power supply. Conclusion: The proposed design is very suitable for the realization of analog signal processing blocks in complementary MOSFET integrated circuits.
\end{abstract}

Key words: Passband ripple, stopband attenuation, switched-capacitor filte

\section{INTRODUCTION}

The most popular approach for realizing analog signal processing in MOS (or BICMOS) integrated circuits is through the use of switched-capacitor circuits $^{[1-4]}$. A switched-capacitor circuit operates as a discrete-time signal processor. As a result, these circuits are most easily analyzed with the use of Z-transform techniques and typically require anti-aliasing and smoothing filters.

As a filtering technique, switched-capacitor circuits have become extremely popular due to their accurate frequency response as well as good linearity and dynamic range. Accurate discrete- time frequency responses are obtained since filter coefficients are determined by capacitance ratios which can be set quite precisely in an integrated circuit (on the order of $0.1 \%)^{[5]}$. Such an accuracy is orders of magnitude better than that which occurs for integrated RC time constants (which can vary by as much as 20\%). Once the coefficients of a switched-capacitor discrete-time filter are accurately determined, its overall frequency response remains a function of the clock (or sampling) frequency. Fortunately, clock frequencies can also be set very precisely through the use of a crystal oscillator.

In this study, a switched-capacitor filter with a high stop band attenuation and low passband ripple is proposed and analyzed. The proposed fifth-order lowpass filter includes three cascaded stages. The first stage is the first order (linear) filter. The second stage is the high Q Biquad filter, while the third stage is the low
Q Biquad filter. The proposed circuit has a stop band attenuation of $53 \mathrm{~dB}$, a passband ripple less than $0.1 \mathrm{~dB}$ and a cut-off frequency of $5 \mathrm{KHz}$.

\section{MATERIALS AND METHODS}

Architecture and circuit implementation: The designed fifth-order switched-capacitor low-pass filter consists of three cascaded stages. The first stage is the first order (linear) filter. The output of this linear filter is connected to the input of the high Q Biquad filter which in turn is connected to the input of the low $\mathrm{Q}$ Biquad filter. Each of the three stages was realized using operational amplifiers, capacitors, switches and non-overlapping clocks. A brief description of the utilized circuits follows.

First-order filter: A general first-order active-RC filter is shown in Fig. 1. To obtain a switched-capacitor filter having the same low-frequency behavior, the resistors are replaced with delay-free switched capacitors, while the nonswitched capacitor feed in is left unchanged. The resulting first-order switched-capacitor filter is also shown in Fig. 1. The transfer function for this filter is found to be:

$$
\mathrm{H}_{1}(\mathrm{z})=\frac{\mathrm{V}_{\mathrm{O}}(\mathrm{z})}{\mathrm{V}_{\mathrm{i}}(\mathrm{z})}=\frac{\frac{\mathrm{C} 1+\mathrm{Ca}}{\mathrm{Ca}} \mathrm{Z}-\frac{\mathrm{C} 1}{\mathrm{Ca}}}{\left(1+\frac{\mathrm{C} 3}{\mathrm{Ca}}\right) \mathrm{Z}-1}=\frac{0.15 \mathrm{Z}-0.05}{1.1 \mathrm{Z}-1}
$$

Corresponding Author: Moussa Abdallah, Department of Electronics Engineering, Princess Sumaya University for Technology, P.O. Box 1438, Amman, 11941 Jordan 


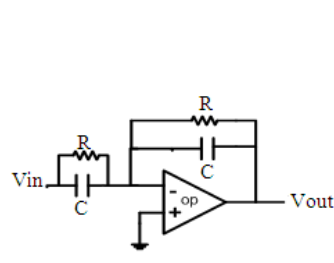

First-order attractive-RC filter

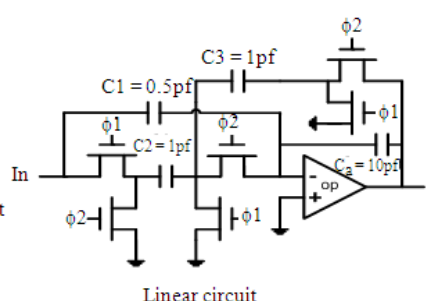

(a)

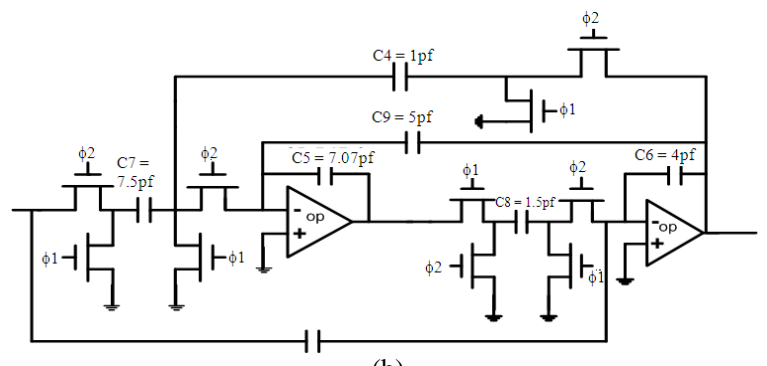

(b)

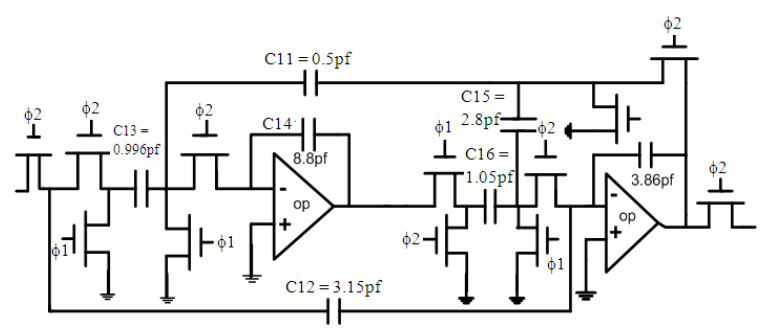

(c)
Fig. 1: Schematic of the switched-capacitor filter, (a): First order filter; (b): High Q biquad filter; (c): Low Q Biquad filter

Biquad filters: Similar to the first-order case, good switched-capacitor Biquad filter structures can be obtained by emulating well-known continuous-time filter structures. However, also as in the first-order case, once a filter structure is obtained, its precise frequencyresponse is determined through the use of discrete-time analysis using the signal-flow-graph technique. This exact transfer function is then used when determining capacitor ratios during the design phase.

Figure $1 \mathrm{~b}$ shows the circuit diagram of the utilized high-Q switched-capacitor filter whose transfer function is found to be:

$$
\mathrm{H}_{2}(\mathrm{Z})=\frac{\mathrm{K}_{3} \mathrm{Z}^{2}+\left(\mathrm{K}_{1} \mathrm{~K}_{5}+\mathrm{K}_{2} \mathrm{~K}_{5}-2 \mathrm{~K}_{3}\right) \mathrm{Z}+\left(\mathrm{K}_{3}-\mathrm{K}_{2} \mathrm{~K}_{5}\right)}{\mathrm{Z}^{2}+\left(\mathrm{K}_{4} \mathrm{~K}_{5}+\mathrm{K}_{5} \mathrm{~K}_{6}-2\right) \mathrm{Z}+\left(1-\mathrm{K}_{5} \mathrm{~K}_{6}\right)}
$$

Substituting $\mathrm{K}_{1}=0.07, \mathrm{~K}_{2}=0, \mathrm{~K}_{3}=0.114, \mathrm{~K}_{4}=0.14$, $\mathrm{K}_{5}=0.34, \mathrm{~K}_{6}=0.707$, into (2) yields:

$$
\mathrm{H}_{2}(\mathrm{Z})=\frac{0.114 \mathrm{Z}^{2}-0.204 \mathrm{Z}+0.114}{\mathrm{Z}^{2}-1.73 \mathrm{Z}+0.76}
$$

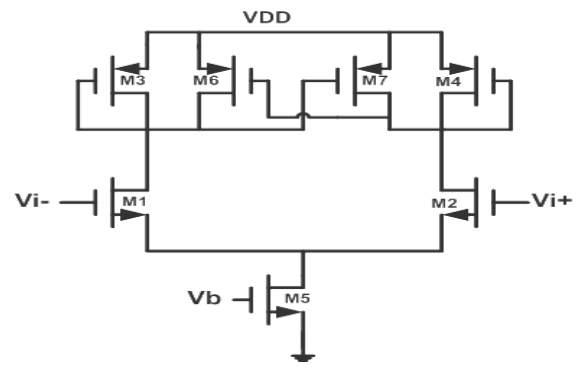

Fig. 2: Circuit diagram of the used op-amp

Figure 1c shows the circuit diagram of the utilized low-Q switched-capacitor filter whose transfer function is found to be:

$$
\mathrm{H}_{3}(\mathrm{Z})=\frac{\left(\mathrm{K}_{2}+\mathrm{K}_{3}\right) \mathrm{Z}^{2}+\left(\mathrm{K}_{1} \mathrm{~K}_{5}-\mathrm{K}_{2}-2 \mathrm{~K}_{3}\right) \mathrm{Z}+\mathrm{K}_{3}}{\left(1+\mathrm{K}_{6}\right) \mathrm{Z}^{2}+\left(\mathrm{K}_{4} \mathrm{~K}_{5}-\mathrm{K}_{6}-2\right) \mathrm{Z}+1}
$$

Substituting $\mathrm{K}_{1}=0.113, \mathrm{~K}_{2}=0, \mathrm{~K}_{3}=0.86, \mathrm{~K}_{4}=$ $0.057, \mathrm{~K}_{5}=0.272, \mathrm{~K}_{6}=0.725$ into the above equation yields:

$$
\mathrm{H}_{3}(\mathrm{Z})=\frac{.816 \mathrm{Z}^{2}-1.6 \mathrm{Z}+.816}{1.725 \mathrm{Z}^{2}-2.71 \mathrm{Z}+1}
$$

Operational amplifier: Figure 2 shows the circuit diagram of the utilized operational amplifier. This single-stage op amp has high output impedance, a high dc gain despite the lack of an output buffer stage since the load of this op amp is purely capacitive. Moreover, this op amp has a high slew rate in order not to limit the clock rate since in this case the charge has to transfer quickly from one capacitor to another ${ }^{[6]}$.

\section{RESULTS}

The Z-domain transfer function of the resultant fifth-order filter is the multiplication of the individual transfer functions of the three former filters:

$$
\begin{aligned}
& \mathrm{H}(\mathrm{Z})=\mathrm{H}_{1}(\mathrm{Z}) \cdot \mathrm{H}_{2}(\mathrm{Z}) \cdot \mathrm{H}_{3}(\mathrm{Z})= \\
& \left(\frac{0.15 \mathrm{Z}-0.05}{1.1 \mathrm{Z}-1}\right)\left(\frac{0.114 \mathrm{Z}^{2}-0.204 \mathrm{Z}+0.114}{\mathrm{Z}^{2}-1.73 \mathrm{Z}+0.76}\right) \\
& \left(\frac{0.816 \mathrm{Z}^{2}-1.6 \mathrm{Z}+0.816}{1.725 \mathrm{Z}^{2}-2.71 \mathrm{Z}+1}\right)
\end{aligned}
$$

Where:

$\mathrm{Z}=\mathrm{COS}(\mathrm{WT})+\mathrm{JSIN}(\mathrm{WT})$

$\mathrm{Z}^{2}=\operatorname{COS}(2 \mathrm{WT})+\mathrm{JSIN}(2 \mathrm{WT})$

$\mathrm{W}=$ Angular frequency

$\mathrm{T}=$ Sampling period 




Fig. 3: Frequency response of the switched capacitor filter

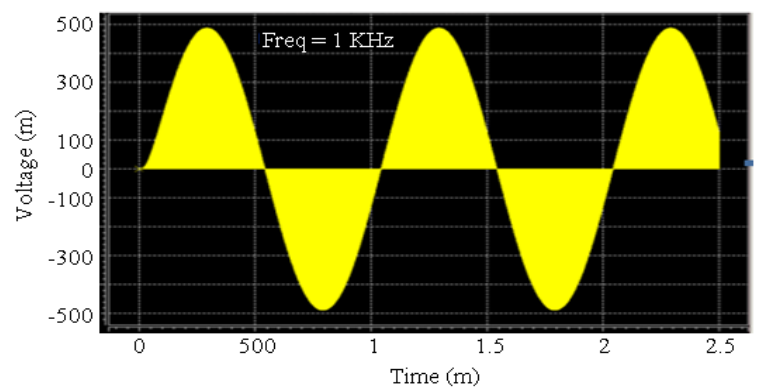

(a)

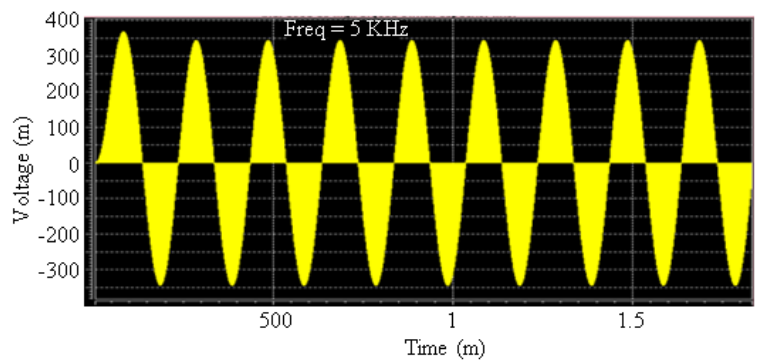

(b)

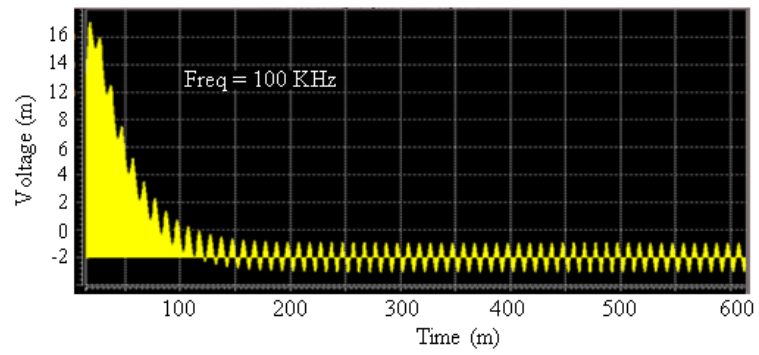

(c)

Fig. 4: Transient response of the filter, (a): At 100 $\mathrm{KHz}$; (b): At $5 \mathrm{KHz}$; (c): At $100 \mathrm{KHz}$

The Z-domain transfer function of (6) is plotted and compared with the output frequency response of the implemented switched capacitor filter as shown in Fig. 3 and Table 1. The obtained results show clearly that the two curves are almost identical and the cutoff frequency of the filter is $5 \mathrm{KHz}$.

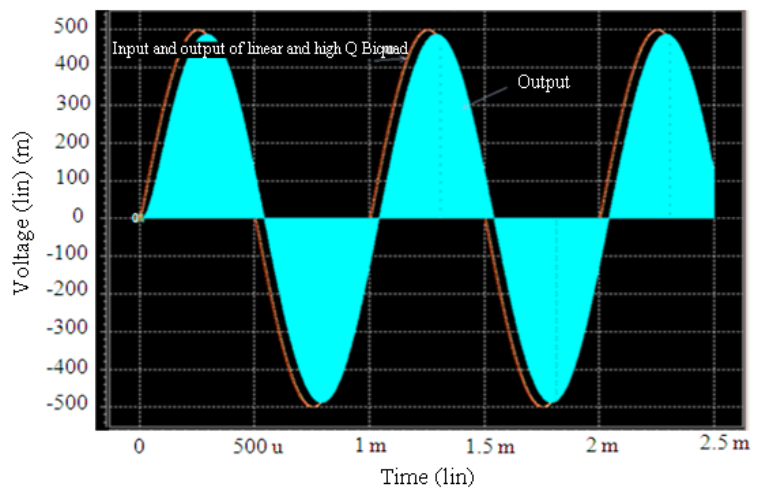

Fig. 5: Transient response of the filter at the outputs of the different circuits constituting the filter

Table 1: Variation of gain versus frequency for the filter

\begin{tabular}{lcc}
\hline Frequency & Pre-simulation gain $(\mathrm{dB})$ & Simulated gain $(\mathrm{dB})$ \\
\hline $10 \mathrm{~Hz}$ & 0.00 & 0.00 \\
$100 \mathrm{~Hz}$ & -0.06 & -0.04 \\
$1 \mathrm{KHz}$ & -0.25 & -0.20 \\
$5 \mathrm{KHz}$ & -3.25 & -3.05 \\
$10 \mathrm{KHz}$ & -8.50 & -8.05 \\
$50 \mathrm{KHz}$ & -48.00 & -47.50 \\
$100 \mathrm{KHz}$ & -53.00 & -53.40 \\
$1 \mathrm{MHz}$ & -53.90 & -53.47 \\
$10 \mathrm{MHz}$ & -59.00 & -57.70 \\
\hline
\end{tabular}

Table 2: Technical specifications the designed filter

\begin{tabular}{lll}
\hline Specification & Required & Achieved \\
\hline Technology & $0.18 \mu \mathrm{m}$ CMOS & $0.18 \mu \mathrm{m} \mathrm{CMOS}$ \\
Power supply & $2 \mathrm{~V}$ & $2 \mathrm{~V}$ \\
Sampling frequency & $1536 \mathrm{KHz}$ & $1536 \mathrm{KHz}$ \\
Cut-off frequency & $5 \mathrm{KHz}$ & $5 \mathrm{KHz}$ \\
Pass band gain & $0 \mathrm{~dB}$ & $0 \mathrm{~dB}$ \\
Pass band ripple & $1 \mathrm{~dB}$ & Less than $0.1 \mathrm{~dB}$ \\
Stop band freq. & $100 \mathrm{KHz}$ & $100 \mathrm{KHz}$ \\
Stop band attenuation & $50 \mathrm{~dB}$ & $53 \mathrm{~dB}$ \\
Input, output swing & $1 \mathrm{~V}$ & $1 \mathrm{~V}$ \\
\hline
\end{tabular}

The transient response of this filter at 1,5 and $100 \mathrm{KHz}$ is shown in Fig. 4. As can be seen the stop band attenuation is $53 \mathrm{~dB}$.

Figure 5 shows the transient response at the output of the three cascaded filters constituting the designed switched-capacitor filter.

In Table 2, the simulated results for the designed switched-capacitor filter are summarized.

\section{DISCUSSION}

Table 2 shows the required specification of the designed stop band all CMOS switched-capacitor filter where it is based on $0.18 \mu \mathrm{m}$ technology. The achieved values are even better, for example, the passband ripple is less than $0.1 \mathrm{~dB}$. Figure 3, shows the frequency response of the filter after implementation and the 
results are very close to the simulated values. Figure 4 shows the time domain response at various frequencies. The low pass filter designed and implemented is small in size and compact.

\section{CONCLUSION}

A $2 \mathrm{~V}$ CMOS switched-capacitor filter has been designed and simulated using $0.18 \mu \mathrm{m}$ CMOS technology. The simulation results indicate that the proposed Filter has a stop band attenuation of $53 \mathrm{~dB}$, a passband ripple less than $0.1 \mathrm{~dB}$ and a cut-off frequency of $5 \mathrm{KHz}$.

This design is very suitable for the realization of analog signal processing blocks in MOS integrated circuits such as voltage-controlled oscillators and modulators.

\section{REFERENCES}

1. Martin, K. and A.S. Sedra, 1981. Swtichedcapactior building blocks for adaptive systems. IEEE Trans. Circ. Syst., 6: 576-84. http://ieeexplore.ieee.org/xpls/abs_all.jsp?arnumbe $\mathrm{r}=1085017$
2. Fried, D., 1972. Analog sample-data filters. IEEE. J. Solid-State Circ., 7: 302-304. http://ieeexplore.ieee.org/xpl/freeabs_all.jsp?arnum ber $=1050305$

3. Caves, J. and C. Rahim, 1977. Sampled-data filters using switched capacitors as resistors equivalents. IEEE J. Solid-State Circ., 12: 592-600.

4. Hosticka, J., R.W. Broderson and P.R. Gray, 1977. MOS sampled data recursive filters using switched-capacitor integrators. IEEE J. Solid-State Circ., 12: 600-608.

http://ieeexplore.ieee.org/xpl/freeabs_all.jsp?arnum ber $=1050967$

5. Jones, D. and Ken Martin, 1997. Analog Integrated Circuit Design. John Wiley and Sons, Inc., ISBN: 0471144487, pp: 706

6. Brackett, P.O. and A.S. Sedra, 1978. Filter Theory and Design: Active and Passive. Matrix Publishers, Champaign, Illinois, ISBN: 0916460142, pp: 785. 